\title{
NUEVA APORTACIÓN A LA OBRA DE MORALES: CRONOLOGÍA, SOPORTES Y RÉPLICAS
}

\author{
IsABel Mateo GómeZ
}

\begin{abstract}
Se aportan tres nuevas versiones del Ecce Homo, pintados sobre distinto soporte, y una Magdalena, réplica de la tabla de la Clerecía de Salamanca.

Palabras clave: Inédito; Soportes; Ecce Homo; Magdalena.
\end{abstract}

\section{A NEW CONTRIBUTION TO THE WORK OF MORALES: CHRONOLOGY,} SUPPORTS \& REPLICAS

The author studies three new versions of the Ecce Homo, painted on different supports, and a replica of the Mary Magdalene from the Clerecía of Salamanca.

Key words: Unpublished; Supports; Ecce Homo; Mary Magdalen.

La singularidad de la obra de Morales, en el panorama de la pintura española de la segunda mitad del siglo XVI, ha sido abundantemente subrayada por los estudiosos del pintor. También se ha hecho notar la dificultad a la hora de fijar una cronología de sus obras y para establecer un catálogo razonado de la misma, debido a la gran calidad que se observa en su taller ${ }^{1}$.

Hasta el momento la primera obra fechada que conocemos de Morales es la Virgen del Pajarito, cuya fecha, 1546, aparece pintada sobre la tabla, que en su día sufrió seria restauración, y que pudiera haber afectado a la fecha alterándola respondiendo a 1564, más coherente con otras obras del pintor, acordes con la influencia que por esos años sufrió de Leonardo, a través de los "leonardescos" valencianos.

Se conocen, también, las fechas de los contratos que hizo Morales para los retablos de Arroyo de la Luz (1563), Higuera la Real (1564), Évora (1564) y Plasencia (1567). Las tablas de este periodo además de responder a un mismo momento estilístico, son, a nuestro parecer, importantes, porque las escenas de los grandes retablos sufren fragmentaciones que darán lugar a las pequeñas tablas de devoción, distintivas del pintor ${ }^{2}$.

Angulo señaló que si Juanes fue el pintor del "Salvador eucarístico", Morales lo fue del Ecce Homo, tema que representó de forma variada, y del que el mismo pintor hizo abundantes réplicas,

\footnotetext{
${ }^{1}$ Angulo Íñiguez, 1954, vol. XII: 231. Gaya Nuño, 1991: 9-10. Bäcksbacka, 1962. Marias, 1989: 342-347. Solis, 1999. Mateo Gómez, 2007:7-24.

2 Trapier, 1953.
} 


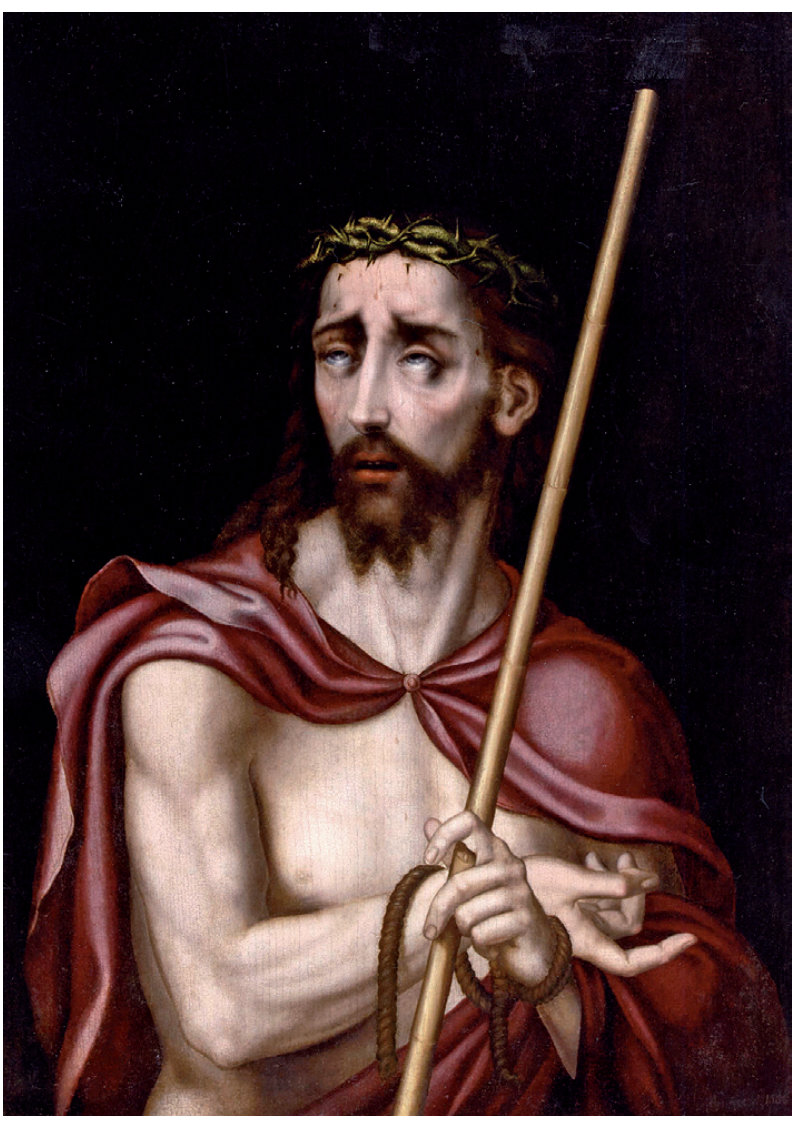

Fig. 1. L. de Morales: Ecce Homo. Madrid. Colección privada.

a veces con la colaboración del taller. Réplicas y copias sirvieron para abastecer a una numerosa clientela, tanto religiosa como seglar, solícita de estos cuadros de "devoción" privada.

Nos parece interesante dar a conocer un Ecce Homo pintado sobre tabla $(83,7$ x 59,5 cm), en el que, después de la limpieza, ha aparecido en el ángulo inferior derecho la firma del pintor y la fecha: “... les fecit a $a^{\circ} 1556$ " (fig. 1), en colección privada madrileña, restaurado en el taller de don Rafael Romero. La tabla de Morales ha sido estudiada antes y después de la restauración, que ha consistido simplemente en una limpieza que ha dejado a la vista un color más brillante. La inscripción con el final del apellido del pintor y la fecha, está integrada en la capa pictórica. En esta tabla Morales presenta a Cristo de medio cuerpo, cubierto por una capa de tono morado, que le cubre los hombros y se abrocha a la altura de las clavículas con un botón. Como característica del pintor el plegado es de aristosos bordes en el manto, las manos con los dedos agarrotados por la presión de las cuerdas, y sujeción de la caña, destacando el dibujo de los nudillos y uñas de los dedos. En la cabeza, evocadora de modelos flamencos, destacan sus ojos azules con lágrimas, elevados al cielo, marcados por el dolor de la corana de espinas, tejida de frescas ramas verdes espinosas que contrasta con el castaño rojizo del cabello y barba, pintados con gran minuciosidad. La entreabierta boca en gesto de dolor, deja ver los dientes. El bien modelado cuerpo, iluminado como el rostro, la capa y la corona, sobresalen sobre el fondo oscuro neutro. La expresión de la cabeza de Cristo es muy similar a la del Cristo de la Crucifixión, en colección privada de Bilbao, en cuya parte inferior aparece un paisaje con un gran peñasco junto a unas ruinas, a través de las cuales se observan unos edificios - tipo fortalezas - que enlazan con un puente con torres entre los ojos, evocándonos al de las Palmas - próximo a Badajoz - por el que corre el Guadiana, y, también, al de Alcántara, en Toledo, similar al que aparece en un Bautismo de Cristo, de Machuca ${ }^{3}$.

El modelo del Ecce Homo, cubierto con capa, debió tener éxito, bien en solitario o acompañado por sayones. Bäcksbacka reprodujo dos similares, al que hemos dado a conocer, fechado en 1556,

\footnotetext{
${ }^{3}$ Bäcksbacka, 1962. Fecha esta Crucifixión de Morales en el año 1572, sugiriendo que pudiera haber formado parte del retablo de una Iglesia de San Felices de los Gallegos. Fue subastada en Sotheby's de Madrid, el 24 de abril de 1997, $\mathrm{n}^{\mathrm{o}} 20$. En prensa se halla el catálogo de la colección bilbaina, donde actualmente se encuentra, obra dirigida por el Profesor Ximo Company. El Bautismo de Machuca fue vendido en Sotheby's de Londres en el 2011, y se reproduce en el citado catálogo.
}

Arch. esp. arte, LXXXVIII, 350, ABRIL-JUNIO 2015, 131-140 ISSN: 0004-0428, eISSN: 1988-8511, doi: 10.3989/aearte.2015.08 


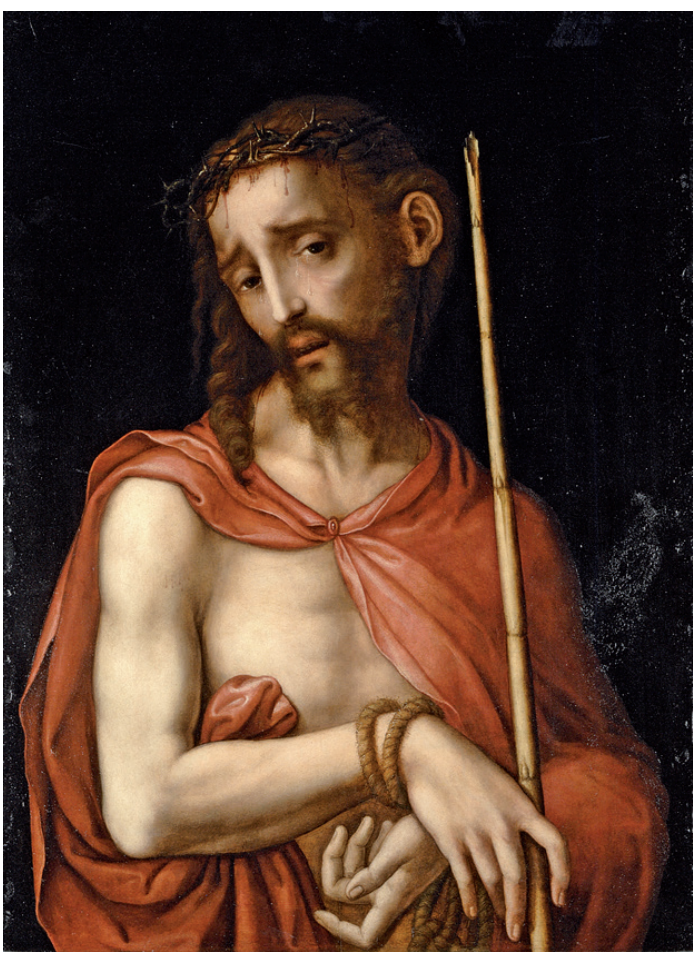

Fig. 2. L. de Morales: Ecce Homo. Madrid. Colección privada.

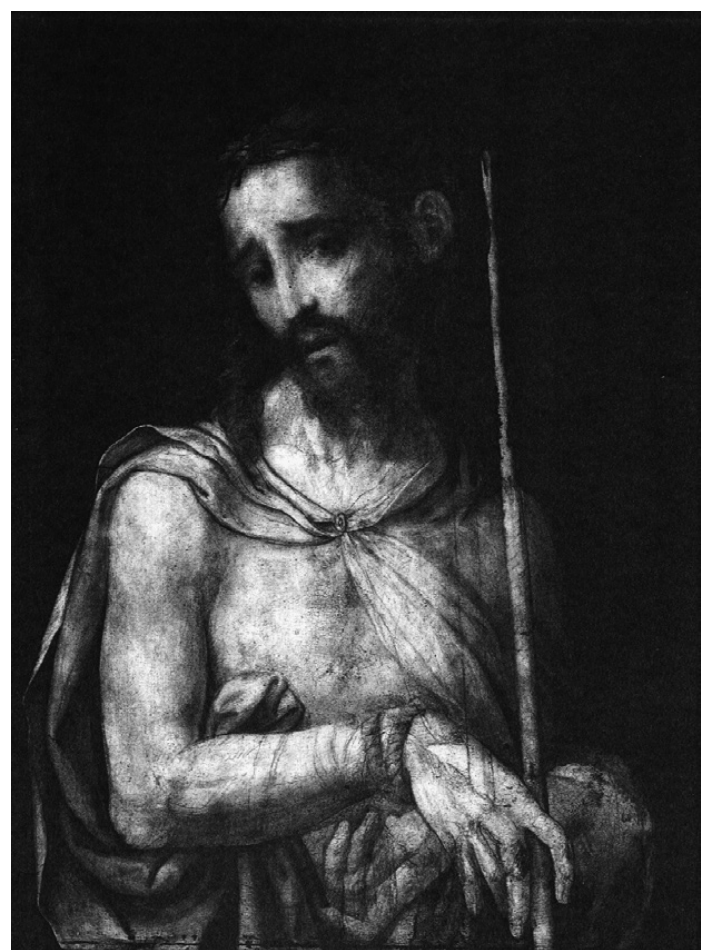

Fig. 3. L. de Morales: Ecce Homo (dibujo subyacente de la figura 2).

en dos colecciones privadas de Barcelona, considerándolas obras de taller ${ }^{4}$. Carmelo Solís, dio a conocer otro ejemplar de taller, localizado en el Museo de Bellas Artes de Málaga ${ }^{5}$. Las diferencias estilísticas entre esta tabla y la que damos a conocer a continuación, puede explicarse por los años transcurridos entre ambas, y por los conocimientos y experiencia adquirida por Morales.

Queremos dar a conocer también en este trabajo, un espléndido Ecce Homo, de la mano de Luis de Morales, cuya autenticidad y calidad va avalada por el dibujo subyacente (figs. 2 y 3). En el dibujo el pintor muestra un trazo seguro en el rostro, plegados, cabellos y manos, a modo de diseño o estructura previa, a la pintura. La corrección del dibujo - en sus contornos, luces y sombras - no cabe duda que facilitó al pintor la aplicación del color y de los detalles más característicos que determinan su estilo, pudiéndose equiparar la seguridad del trazo y la presencia de "arrepentimientos" a los observados en los grandes maestros, anteriores y posteriores al maestro extremeño.

La cabeza de este Ecce Homo es hermosa y sobrecogedora, evocándonos a la pintada por Morales en el Cristo de la Última Cena, que se conserva en el Museo Ursino, de Catania (Italia), cuya fotografía reproduce Gaya Nuño en su libro. El contenido gesto de dolor del Ecce Homo, presta belleza al rostro, recordándonos, junto al giro de la cabeza, el atirabuzonado tratamiento del cabello, y la visible oreja, algunos modelos del Piombo, como el Ecce Homo, que se conserva en

\footnotetext{
${ }^{4}$ Bäcksbacka, 1962: no cat. A19 y A20.

${ }^{5}$ Solis, 1999.
}

Arch. esp. arte, LXXXVIII, 350, ABRIL-JUNIO 2015, 131-140

ISSN: 0004-0428, eISSN: 1988-8511, doi: 10.3989/aearte.2015.08 


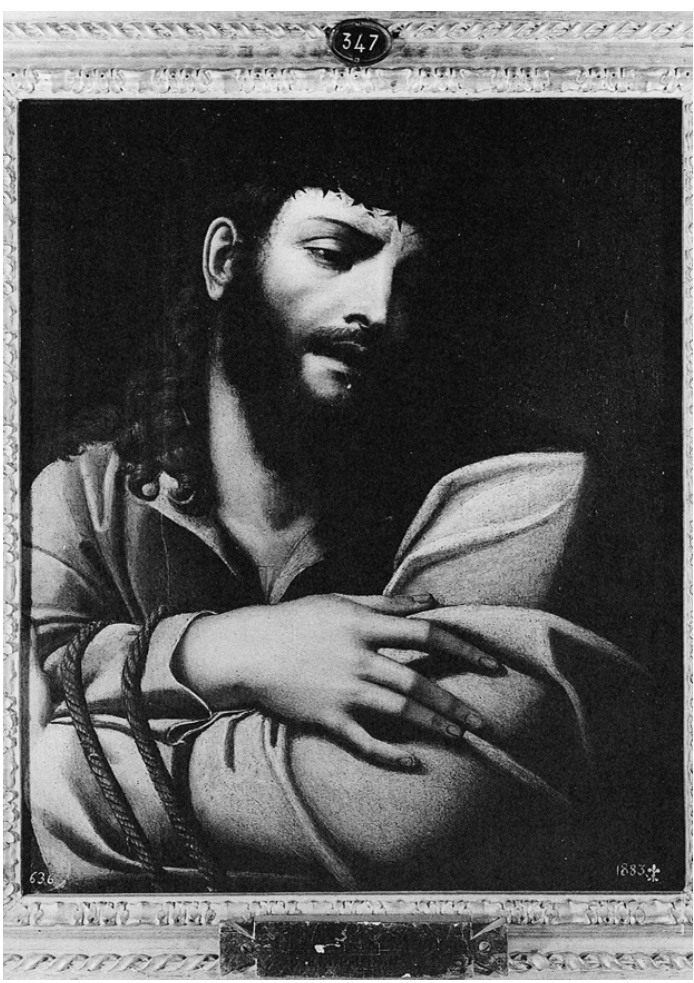

Fig. 4. S. del Piombo: Ecce Homo. Madrid. Museo del Prado (Foto Instituto Amatller de Barcelona).

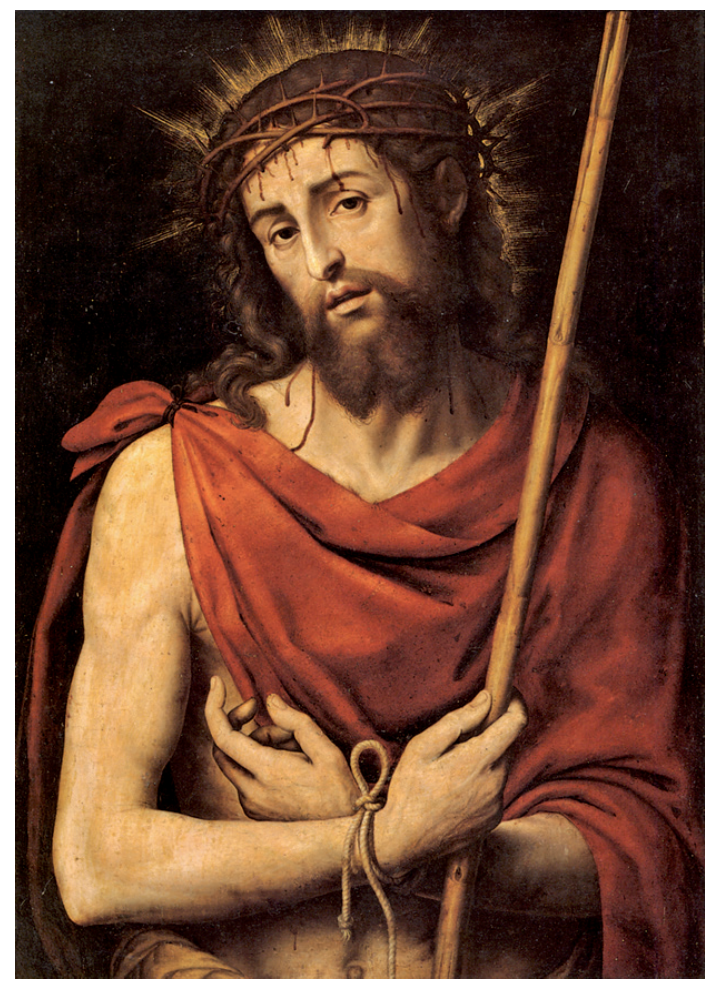

Fig. 5. Juan de Juanes: Ecce Homo. Valencia. Museo de Bellas Artes.

el Prado (fig. 4). También se advierte en la tabla de Morales el conocimiento de la obra de Juan de Juanes (fig. 5), composición considerada como obra del pintor valenciano hacia mediados de siglo.

Morales pinta el Ecce Homo, al óleo sobre tabla de nogal, siendo sus medidas 73,1 x 52,1 cm. Esta tabla estuvo expuesta en Christie's de Madrid en 2007, hallándose actualmente en colección privada madrileña. Cristo destaca sobre un fondo oscuro neutro, y en el tratamiento de la cabeza podemos percibir toda la exquisitez de la que es capaz el maestro, en el tratamiento minucioso del cabello, lágrimas y boca entreabierta dejando atisbar los dientes. El movimiento de la figura, el color anaranjado-rojizo del manto, le pone también en relación con el pintor manierista flamenco, Cornelius Cyaneus, establecido en Toledo, que pintó en 1562 el retablo de San Pedro (fig. 6) para la iglesia de Villar del Pedroso, en la provincia de Cáceres ${ }^{6}$. En efecto cuando F. Benito, describe las características del Ecce Homo de Juanes, parece estar refiriéndose a los de Morales, “... centrado el interés en la figura de Cristo, con una mirada cautivadora, capaz de suscitar el diálogo con el espectador de forma espiritual e intimista; por su minuciosidad a la flamenca" ${ }^{\text {"7 }}$. Teniendo en cuenta esta descripción podríamos establecer como diferencia ente ambos pintores, el dramatismo expresivo del incipiente manierismo que observamos en el Ecce Homo moraliano, más propicio al diálogo meditativo del espectador sobre su "pasión", que el de Juanes.

\footnotetext{
${ }^{6}$ Sobre Cornelio Cyaneus se halla en prensa un trabajo de Isabel Mateo Gómez, para el Homenaje al Canónigo Archivero de la Catedral de Toledo, D. Ramón Gonzálvez.

${ }^{7}$ Benito Domenech, 2000.
}

Arch. esp. arte, LXXXVIII, 350, ABRIL-JUNIO 2015, 131-140 ISSN: 0004-0428, eISSN: 1988-8511, doi: 10.3989/aearte.2015.08 


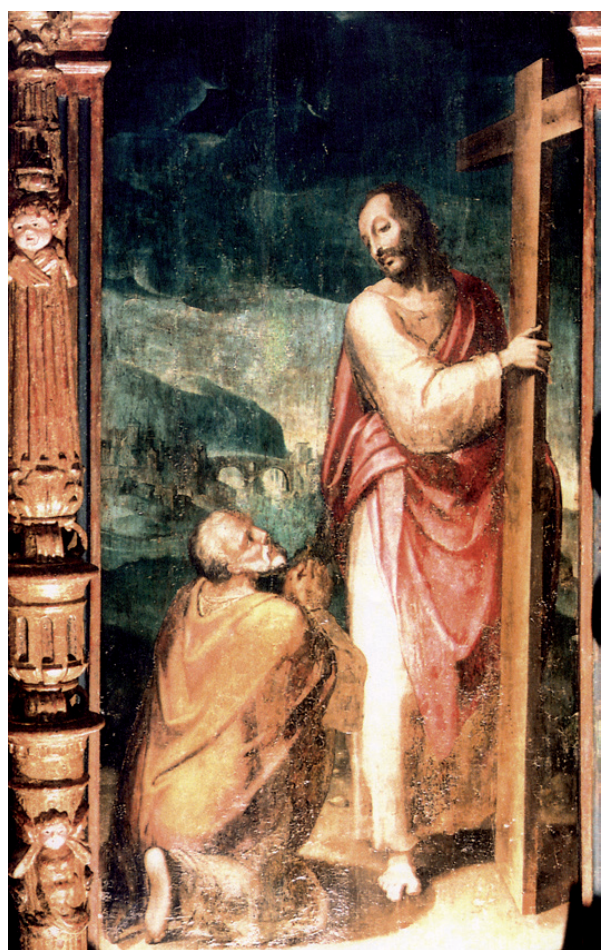

Fig. 6. Cornelio Cyaneus: ¿Quo Vadis? Villar del Pedroso (Cáceres). Iglesia de San Pedro. Retablo.

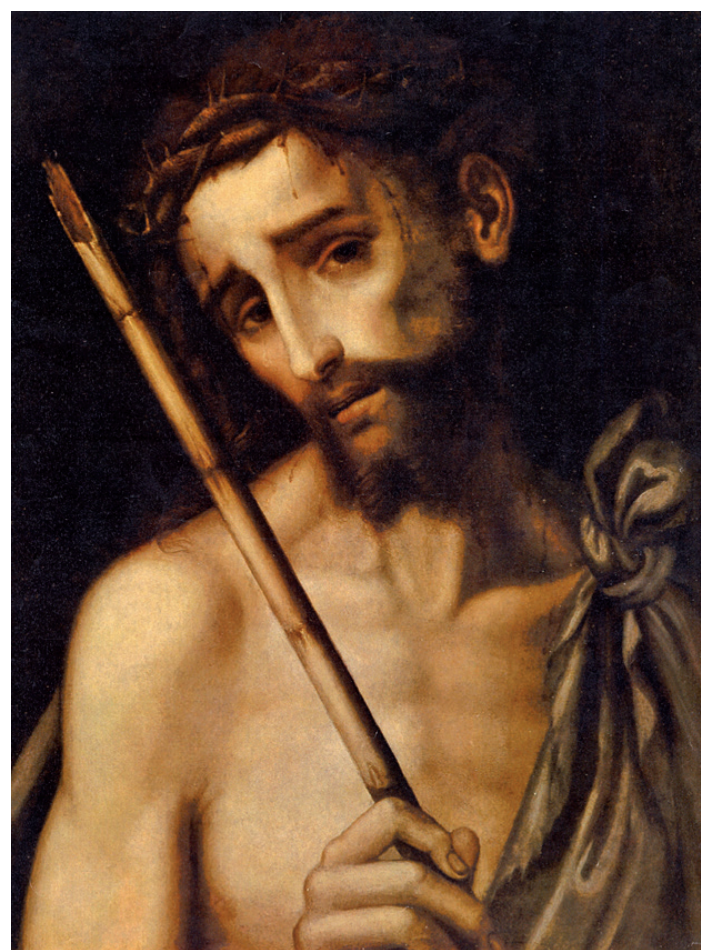

Fig. 7. L. de Morales: Ecce Homo. Madrid. Colección privada.

El Ecce Homo de Morales (fig. 2), creo que debería fecharse entre 1564 y 1569, después de la marcha de su protector el arzobispo don Juan de Ribera, a Valencia, y para el que pinta en esa ciudad y por esos años. En el reverso de la tabla se puede leer, "Divino Morales fecit", apelativo que le daban al pintor en la cumbre de su carrera, que no aparece en la tabla del Ecce Homo de 1556.

Un tercer Ecce Homo de Morales, queremos dar a conocer, por la singularidad del soporte: cobre (fig. 7). Se halla en colección privada madrileña y sus medidas son 41,7 x $31,7 \mathrm{~cm}$, las utilizadas por el pintor generalmente para sus pequeños formatos de "piedad privada". La utilización del cobre como soporte nos indica el interés de Morales por la experimentación, materia que, como dice Bargellini, no solo fue utilizado por los flamencos, sino por los pintores europeos, extendiéndose a todo el Nuevo Mundo ${ }^{8}$. Sobre cobre pintó el Piombo, quien sin duda influyó en Morales, según hemos podido comprobar en un pequeño óvalo de cobre pintado por él, para un ostensorio (en estudio, I. Mateo). En Sevilla, ciudad próxima al Badajoz de Morales, la presencia de los cuadritos "piadosos" en soporte de cobre, de Marcelus Coffermans, pudieron invitar, también, a Morales y Pacheco, a pintar sobre este tipo de material en dos ocasiones. Sabemos que los cobres de Coffermans se difundieron por España, pero desconocemos el número de pintores que se sintieron atraídos por pintar sobre esta materia. En el caso de Morales y Pacheco muestran menos calidad que en su obra restante.

\footnotetext{
${ }^{8}$ Bargellini, 1999: 79-98. Bermejo, 1982: 3-8. Valdivieso/Serrera, 1985. Komanecky, 1999. Efectivamente en los tres Ecce Homo, de Morales que hemos dado a conocer el soporte ha sido distinto: roble, nogal y cobre. También debería considerarse para llevar a cabo un catálogo razonado de la obra de Morales y de su taller, la utilización del dibujo subyacente, aunque sea costoso el proceso.
}

Arch. esp. arte, LXXXVIII, 350, ABRIL-JUNIO 2015, 131-140

ISSN: 0004-0428, eISSN: 1988-8511, doi: 10.3989/aearte.2015.08 


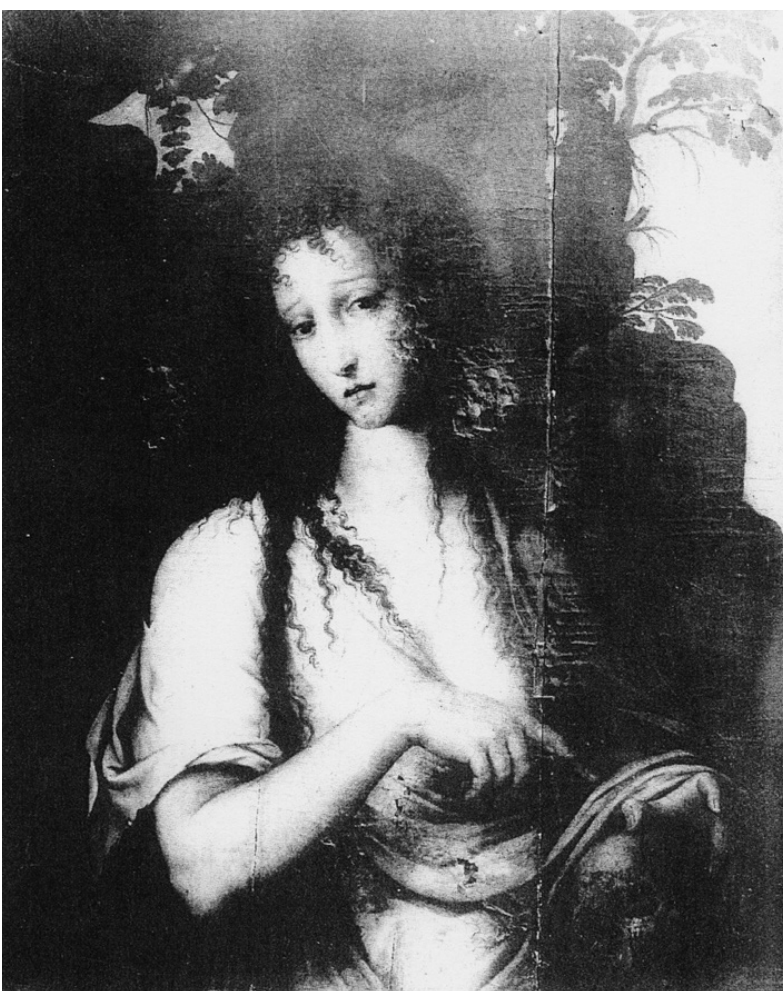

Fig. 8. L. de Morales: La Magdalena. Salamanca. Clerecía.

En el anverso y reverso del soporte de cobre aparecen diversos tipos de oxidaciones propias de los colores, a modo de pequeños puntos negros bajo los cuales no hay pintura. Para pintar el cobre se cubre con una pequeña capa fina de color blanco, de plomo mezclado con aceite de linaza consiguiéndose veladuras, sobre ella va el dibujo y después el óleo. La técnica de la pintura en cobre data del siglo XVI, y sus finas hojas facilitan trabajos minuciosos.

Siempre se invocan como fuentes para la iconografía del Ecce Homo, los pasajes de Isaías (50, 4-11), San Juan (19,1-16) y Mateo (27,27-29). Davies -en 1984- y Rodríguez G. de Ceballos -en 1987- subrayaron respectivamente, la importancia de la espiritualidad española en la época de El Greco y de Morales, coincidente con la Contrarreforma, que abocó hacia un tipo de oración interior y hacia la penitencia, convirtiéndose en su máximo exponente la literatura mística, en su búsqueda de una experiencia directa con la divinidad ${ }^{9}$. A propósito de todo ello no debemos olvidar, como precedente, un pasaje de Isaías poco citado, en el que se refiere al Mesías, como ser "paciente" y "glorificado"; será ensalzado y engrandecido y llegará a la cumbre misma de la gloria: “...Al modo que tú, Oh Jerusalén fuiste en tu ruina el asombro de muchos; así también su aspecto parecerá sin gloria delante de los hombres, y en una forma despreciable entre los hijos de los hombres. Él rociará o purificará a muchas naciones... no es de aspecto bello ni es esplendoroso; le hemos visto, y nada hay que atraiga nuestros ojos, ni llame nuestra atención hacia él; despreciado, y el deshecho de los hombres, varón de dolores, y que sabe lo que es padecer; y su rostro como cubierto de vergüenza y afrentado por lo que no hicimos ningún caso de él... cargó con nuestras penalidades; pero nosotros los refutamos como un leproso, y como un hombre herido de la mano de Dios, herido y humillado. Siendo asi que por causa de nuestras iniquiades fue llagado, y despedazado por nuestras maldades; el castigo que debía hacer nuestra paz con Dios descargó sobre él y con sus cardenales fuimos nosotros curados...". Los textos bíblicos del Antiguo y del Nuevo Testamento fundamentan la literatura mística de Isabel de Villena, Teresa de Jesús, Fray Luis de Granada, San Juan de Ávila, etc., en los que se intercambian preocupaciones de religiosidad "interior" y "pasionaria", a las que habría de sumarse la obra del extremeño Vasco Díaz Taranco de Frenegal, quien divide su tiempo entre Extremadura y Portugal, hacia 1560, al que pudieron conocer Morales y don Juan de Ribera.

El personaje de la Magdalena aparece pintado por Morales no solo en retablos, formando parte en las escenas de la Vida de Jesús, o como pareja de San Juan en los bancos de estos, o en puertas de trípticos, si no también, en solitario, como la que se encuentra en la Clerecía de Salamanca (fig. 8),

9 Davies, 1984: 57-75. Rodríguez G. De Ceballos, 1987: 194-203.

Arch. esp. arte, LXXXVIII, 350, ABRIL-JUNIO 2015, 131-140 ISSN: 0004-0428, eISSN: 1988-8511, doi: 10.3989/aearte.2015.08 


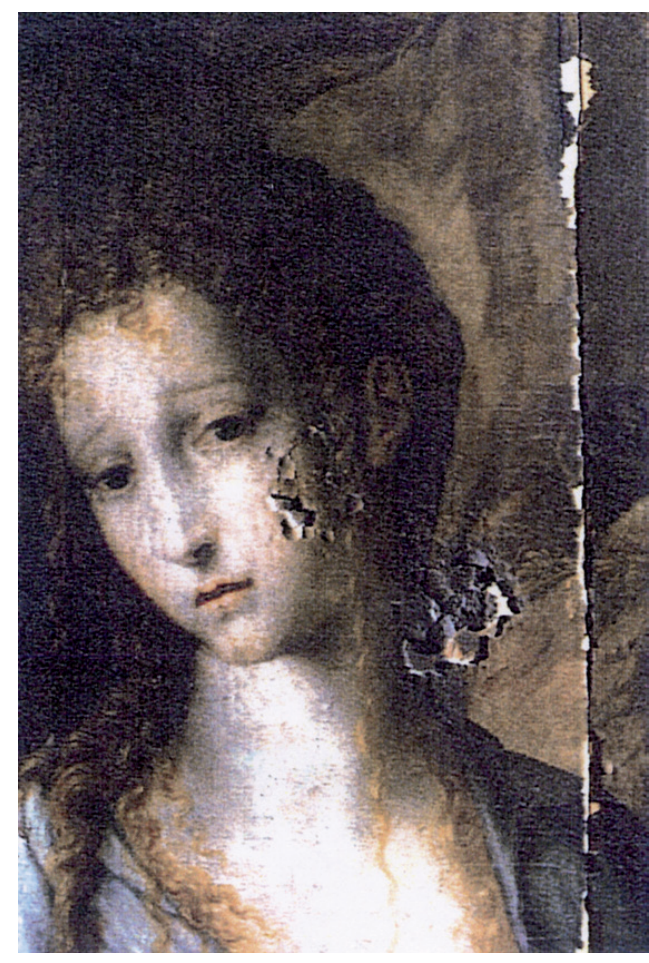

Fig. 9. Idem, detalle antes de la restauración.

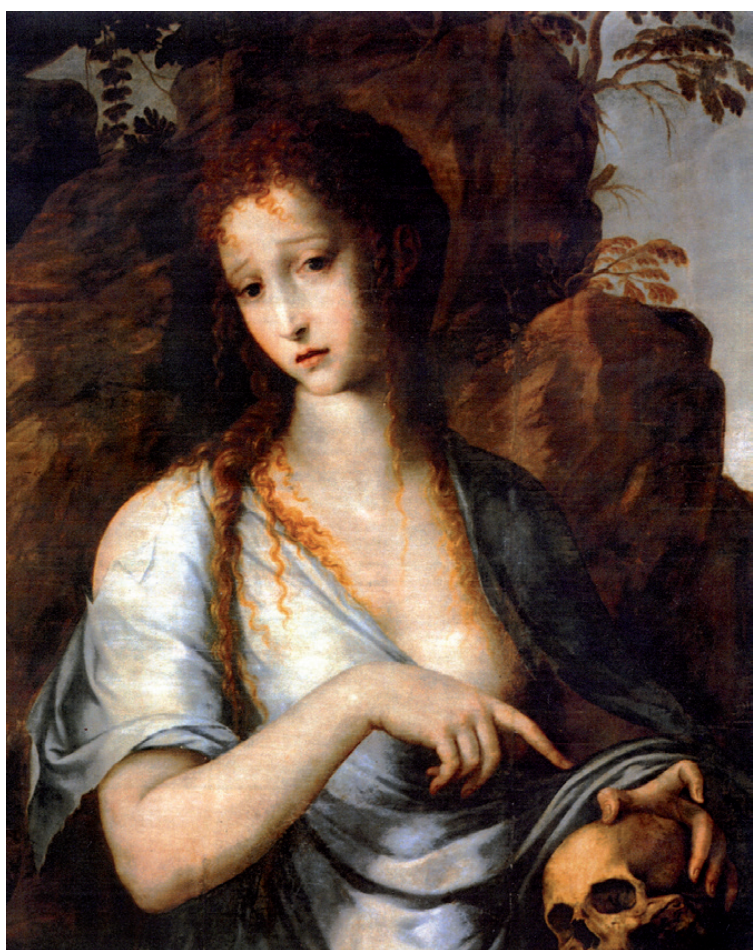

Fig. 10. Idem, después de la restauración.

dada a conocer por Gómez Moreno en su Catálogo Monumental de Salamanca, redactado en 1901, considerándola como obra de escuela italiana, destacando su correcta ejecución, penetrante hermosura y sentimiento, así como evocaciones leonardescas. Gómez Moreno piensa que debió ser pintada en España y viendo en ella ciertas analogías con los modelos de Morales "el de Badajoz" vuelve a ocuparse de esta tabla de la Magdalena hasta que, Ingeld Bäcksbacka en su tesis doctoral sobre Luis de Morales, publicada en 1962, se ocupa de ella, clasificándola como obra dudosa de Morales. En el catálogo utiliza foto de Gómez Moreno, comentando sobre ella que fue pintada para la iglesia de San Marcos de Salamanca, desaparecida en 1955, según información del párroco. Esta tabla según Bäcksbacka estuvo en la Exposición del Divino Morales, celebrada en 1917, en cuyo catálogo aparece con el número $2^{11}$.

La foto de la Magdalena reproducida por Gómez Moreno y Bäcksbacka, nos hace apreciar su mal estado de conservación, que no afecta a las partes esenciales del rostro (fig. 9); además del saltado de la pintura, se observa la suciedad que cubría el tarro de perfume, que se hallaba en el ángulo inferior izquierdo. La Magdalena de la Clerecía está pintada al óleo sobre tabla y mide 104 x $87,5 \mathrm{~cm}$, lo que hace pensar que constituía una tabla de altar. Fue restaurada entre junio de 1991 y julio de 1992, con excelente resultado (fig. 10), pero es curioso como en la publicación que se hizo sobre ella al ser restaurada, no se haya tenido en cuenta la bibliografía existente, dándola como obra anónima de finales del XVII o comienzos del XVIII ${ }^{12}$.

\footnotetext{
${ }^{10}$ Gómez Moreno, 1967: 286, fig.342.

${ }^{11}$ Bäcksbacka, 1962: 366, fig. 170, $\mathrm{n}^{\circ}$ cat. A40.

12 1984-1995. Castilla y León Restaura, 1995: 72.
}

Arch. esp. arte, LXXXVIII, 350, ABRIL-JUNIO 2015, 131-140

ISSN: 0004-0428, eISSN: 1988-8511, doi: 10.3989/aearte.2015.08 


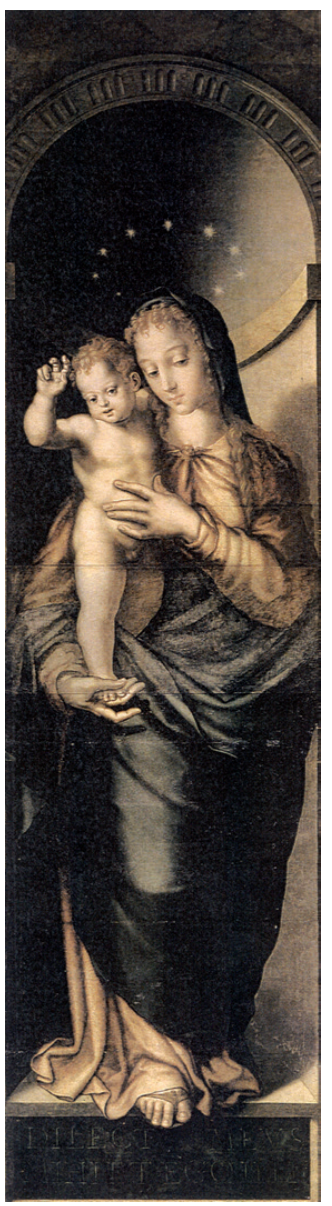

Fig. 11.

L. de Morales:

Virgen con el Niño.

Lisboa. Museo

(Retablo de Évora).

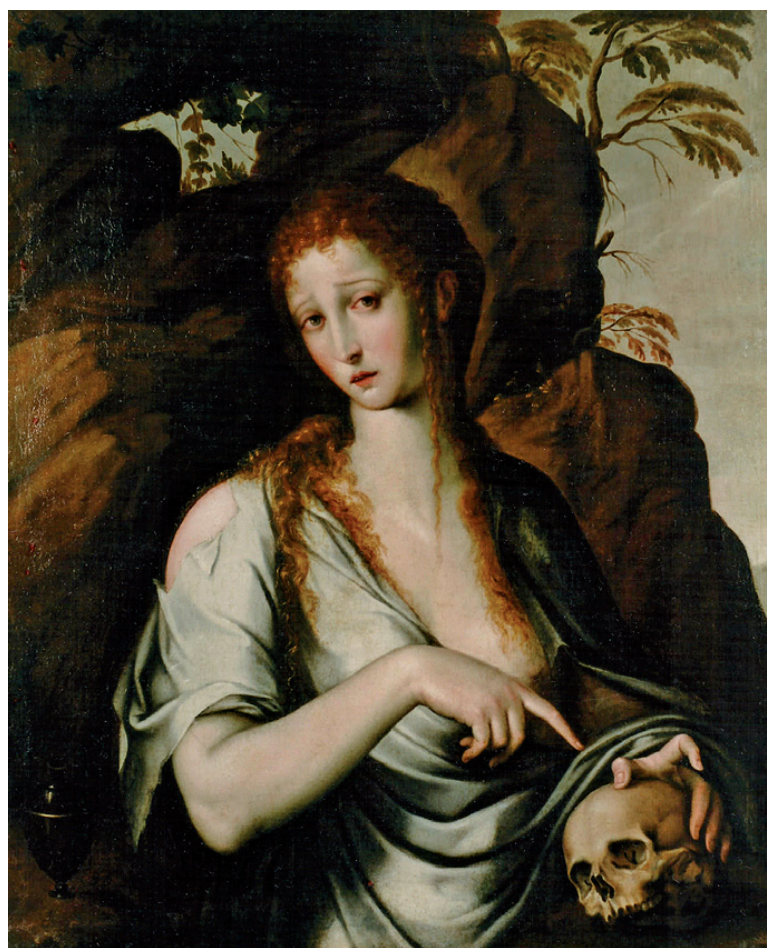

Fig. 12. L. de Morales: La Magdalena. Pontevedra. Colección privada.

Las consideraciones de Gómez Moreno sobre la influencia leonardesca en la Magdalena, la relación del modelo de ésta con los de Morales, y la afirmación de que se trata de una tabla pintada en España, conduce a confirmar la atribución definitiva al maestro extremeño, ya que responde a las características que los estudiosos destacan en él ${ }^{13}$. El modelo "doliente" de la Magdalena se puede poner en relación con otros de Morales, especialmente con los de las Vírgenes del Huso, coincidiendo, además, en el fino tratamiento del cabello, con bucles y mechones a lo largo del rostro, con los que aparecen en la Virgen con el Niño, de Évora (fig. 11).

La Magdalena de Morales señala a la calavera como objeto de meditación siguiendo la tradición de los siglos XV y XVI, recuérdese especialmente la imagen de San Jerónimo y, en literatura, la escena del monólogo de Hamlet. Por estos años la muerte, en sí misma, fue reemplazada por la meditación sobre ella.

Las composiciones, en general, de Morales tuvieron mucho éxito, existiendo réplicas del maestro y copias del taller, según la exigencia del comitente. De la Magdalena de la Clerecía se hicieron varias versiones y copias, pero la que nos parece más interesante, por su calidad, es la que damos a conocer en colección privada de Pontevedra (fig. 12), que consideramos réplica de la mano de

${ }^{13}$ Trapier, 1953. Gaya Nuño, 1961. Solis, 1999. Angulo Íñiguez, 1954, vol. XII: 231. Mateo Gómez, 2007:7-24.

Arch. esp. arte, LXXXVIII, 350, ABRIL-JUNIO 2015, 131-140 ISSN: 0004-0428, eISSN: 1988-8511, doi: 10.3989/aearte.2015.08 
Morales. Se trata de una tabla pintada al óleo $(109 \times 91 \mathrm{~cm})$, que posteriormente, ha sido pasada a lienzo, como se hizo con otra pintura de Morales de Jesús con la cruz a cuestas, acompañado por la Virgen y San Juan, que fue vendida en Alcalá Subastas, de Madrid, en diciembre de 2008.

La Magdalena de Pontevedra ofrece, la misma calidad, en el tratamiento del cabello, dibujo de las manos, textura y plegado de los paños, y color, que la de la Clerecía de Salamanca. El modelado del rostro es exquisito con el doliente fruncimiento del entrecejo y la boca entreabierta dejando ver los delicados dientecillos. Según su propietario actual la adquirió en 1992, atreviéndonos a sugerir que pudiera tratarse del ejemplar desaparecido, en 1955, de la iglesia de San Marcos de Salamanca, ya que parece más fácil la salida de una parroquia, que de la Clerecía.

Ya hemos aludido a cómo el éxito de las obras de Morales propició la copia de taller y de seguidores del maestro, algunas, de calidad, se hallan en colección privada de Lille (Francia), otras en Codos (Zaragoza) y en el Castillo de Javier (Navarra) ${ }^{14}$. El ejemplar de Lille parece ser un retrato a lo "divino" ofreciendo el pintor ciertas novedades de carácter más individual, que la de un simple seguidor o imitador.

Al penitente se le considera como el hombre nuevo que elige la vida ascética como forma de alcanzar la sabiduría, promovido en la Devotio moderna, en la que se promovía la meditación personal frente a una religiosidad basada en el culto. Entre los "penitentes", en solitario, Morales ofrece, además de la Magdalena, muchas versiones de San Jerónimo, unas más anciano y otras menos, lampiño, como el del museo de Dublín. La Magdalena, según San Lucas, derrama un frasco de perfume sobre los pies de Cristo, en el entierro de éste. Luego la Magdalena se retira como penitente, representándose en el arte como una bella pecadora arrepentida, con melena suelta y larga, semidesnuda, orando y meditando ante un crucifijo y calavera, y, junto a ella un frasco de perfume.

Los años, en que se pintan los ermitaños de Morales, y se escribe el Hamlet de Shakespeare, fueron de agitación religiosa coincidentes con el apogeo y finalización de la Contrarreforma. Algunos críticos han visto cierta influencia católica en la obra de Shakespeare, pero, aunque no fuera así, entre los libros que dejó Lutero, de la Biblia Católica, para conformar la Biblia luterana, estaba el Eclesiastés, en el que se meditaba sobre las "vanidades"15.

\section{BIBLIOGRAFÍA}

Angulo Íñiguez, Diego (1954): “La pintura del Renacimiento”. En: (1947-1973) Ars Hispaniae: historia universal del arte hispánico. Madrid: Plus-Ultra.

Bäcksbacka, Ingjald (1962): Luis de Morales. Helsinki: Societas Scientarum Fennica.

Bargellini, Clara (1999): "La pintura sobre lámina de cobre en los Virreinatos de la Nueva España y Perú". En: Anales del Instituto de Investigaciones Estéticas, v. XXI, nº 75, México, pp. 79-98.

Benito Doménech, Fernando (2000): Joan de Joanes. Un maestro del Renacimiento. Valencia: Fundación Santander Central Hispano.

${ }^{14}$ Mateo Gómez, 2003: 301-310. Su calidad y modelo está muy cercana a Luis de Morales. Morte, 2010. Junto a Rolan de Moys llega a la corte de los Villahermosa, Pablo Esquert o Scheppers, quien declara sentir gran atracción por la obra de Morales, del que hizo muchas copias. Mateo Gómez, 2006: 65-84. También debemos recordad en relación con las Magdalenas de Morales las interpretadas por El Greco, años después del extremeño, en Kansas City, Nelson Gallerythe Alkins, Nelson Fund. y en el Worcester Art Museum. Para el tema de los ermitaños véase el trabajo de García Maiques, 2000: 209-223.

15 García Maiques, 2000: 209-223. Mateo Gómez, 2000: 279-304.

Arch. esp. arte, LXXXVIII, 350, ABRIL-JUNIO 2015, 131-140

ISSN: 0004-0428, eISSN: 1988-8511, doi: 10.3989/aearte.2015.08 
Bermejo Martínez, Elisa (1982): “Influencia de una obra flamenca en Pacheco". En: Archivo Español de Arte, LV, no 217, Madrid, pp. 3-8.

(1995): Castilla y León Restaura: 1984-1995: Exposición Monasterio Nuestra Señora del Prado. Valladolid: Junta de Castilla y León.

Davies, David (1984): "El Greco and the spiritual Reform Movements in Spain". En: Studies in the History of Art, $\mathrm{n}^{\circ}$ 13. Washington: National Gallery of Art, pp. 57-75.

Gaya Nuño, Juan Antonio (1961): Luis de Morales. Madrid: Instituto Diego Velázquez.

García Mahíques, Rafael (2000): "Sedes Virtutis Quadrata. Consideraciones sobre la iconografía de los santos penitentes”. En: Zafra, Rafael (ed.) (2000) Emblemata Aurea: la emblemática en el arte y la literatura del siglo de oro. Madrid: Akal, pp. 209-223.

Gómez Moreno, Manuel (1967): Catálogo Monumental. Provincia de Salamanca. Madrid: Dirección General de Bellas Artes.

Komanecky, Michael K. (1999): Copper as Canvas: Two Centuries of Masterpiece Paintings on Copper, 1575-1775. New York: Oxford University Press.

Marías Franco, Fernando (1989): El largo siglo XVI: los usos artísticos del Renacimiento Español. Madrid: Taurus.

Mateo Gómez, Isabel (2000): “Pervivencias clásicas en un emblema del siglo XVII”. En: Zafra, Rafael (ed.) Emblemata Aurea: la emblemática en el arte y la literatura del siglo de oro. Madrid: Akal, pp. 279-304.

Mateo Gómez, Isabel (2007): "Flandes, Portugal y Toledo en la obra de Luis de Morales: Las Vírgenes gitanas o del Sombrero". En: Archivo Español de Arte, LXXX, n 317, Madrid, pp.7-24.

Mateo Gómez, Isabel (en prensa): "Cornelius Cyaneus" En: Homenaje al Canónigo Archivero de la Catedral de Toledo, D. Ramón Gonzálvez.

Pérez Sánchez, A. E. (1979): “Juan de Juanes en su Centenario”. En: Archivo de Arte Valenciano, n 50, Valencia, pp. 5-16.

Rodríguez G. De Ceballos, Alfonso (1987): “El mundo espiritual del pintor Luis de Morales”. En: Goya, n 196, Madrid, pp. 194-203.

Solis, Carmelo (1999): Luis de Morales. Badajoz: Fundación Caja de Badajoz.

Trapier, Elizabeth du Gué (1953): Luis de Morales and the leonardesque influences in Spain. New York: The Hispanic Society of America.

Valdivieso, Enrique / Serrera, Juan Miguel (1985): Pintura sevillana del primer cuarto del siglo XVII. Madrid: Consejo Superior de Investigaciones Científicas.

Fecha de recepción: 03-III-2014

Fecha de aceptación: 10-IX-2014

Arch. esp. arte, LXXXVIII, 350, ABRIL-JUNIO 2015, 131-140 ISSN: 0004-0428, eISSN: 1988-8511, doi: 10.3989/aearte.2015.08 